\title{
Variations in weathering intensity across western Greenland based on radiogenic isotopes
}

Daniel Z. Fischer, Ellen E. Martin, Jonathan B. Martin, Kelly M. Deuerling, Cheyenne Everhart Department of Geological Sciences, University of Florida, Gainesville, FL 32611

\section{$\underline{\text { Results }}$}

\section{Introduction}

Physical weathering of continental ice sheets enhances chemical weathering, which impacts
fluxes of radiogenic isotopes and nutrients to the oceans and atmospheric fluxes of carbon The western margin of Greenland, which represents a region of restreat of a moderm The western margin of Greenland, which represents a region of retreat of a modern
continental ice sheet, provides a good location to assess spatiotemporal variations of glacial weathering environments. These environments include: 1) proglacial watersheds, where the water is sourced directly from the ice sheet, and 2 2 deglaciated watersheds, which are
hyydrologically separated from the ice sheet and only drain precipitation and permatrost - Chemical weathering of tresh material preterentially releases radiogenic Sr and Pb isotopes due to prefererential weathering minerals enriched in radiogenic isotopes and leaching of radiogente Sr and The bedload-water offset decreases as extent of weathering increases, allowing a measure The bedload-water offset cor
of the extent of weathering Scribere ent al. (2015) documented an increase in the extent of weathering across western
Greenland from the ice sheet toward the coast that coincided with inireasing moraine ages and a transition from a negative to positive water balance (see Fig. 1).

As the Greenland Ice Sheet (GrIS) retreats in response to global warming, the proportion of
deglaciated to proglacial watersheds will increase and the water balance will shift inland. These changes in response to ice sheet retreat could account for a documented rapid

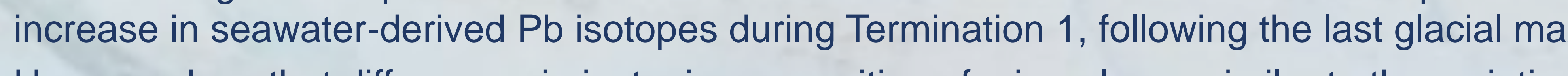
Here we show that differences in isotopic composition of minerals are similar to the variation
in water compositions, suggesting that solid phases may record the geoologic history of ice

\section{Field Area: Western Greenland}
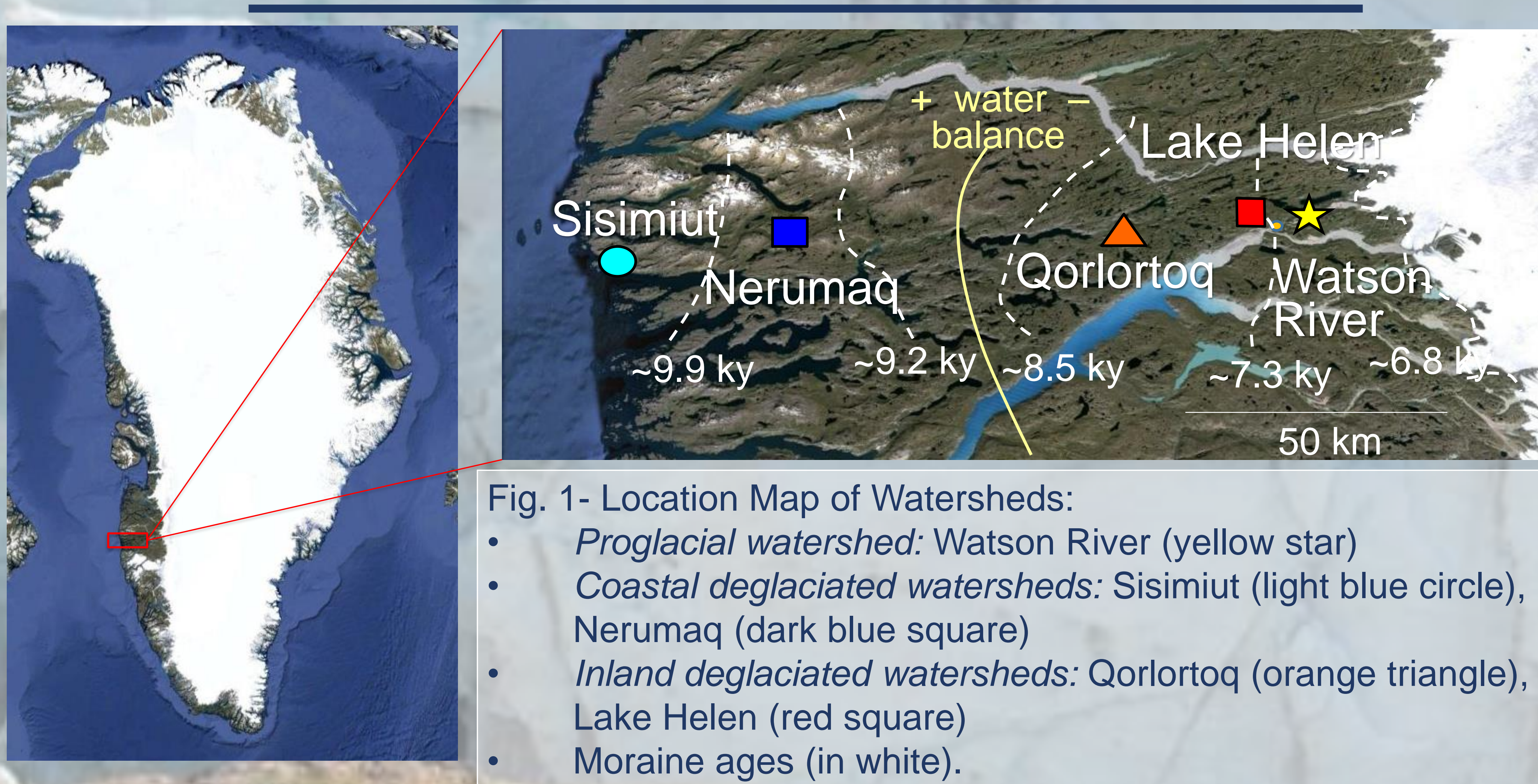

Fig. 1- Location Map of Watersheds:

Proglacial watershed: Watson River (yellow star)

Sisimiut (light blue circle)

Inland deglaciated waters

Lake Helen (red suare
Moraine ages (in white).

Sr Isotope Weathering Trends

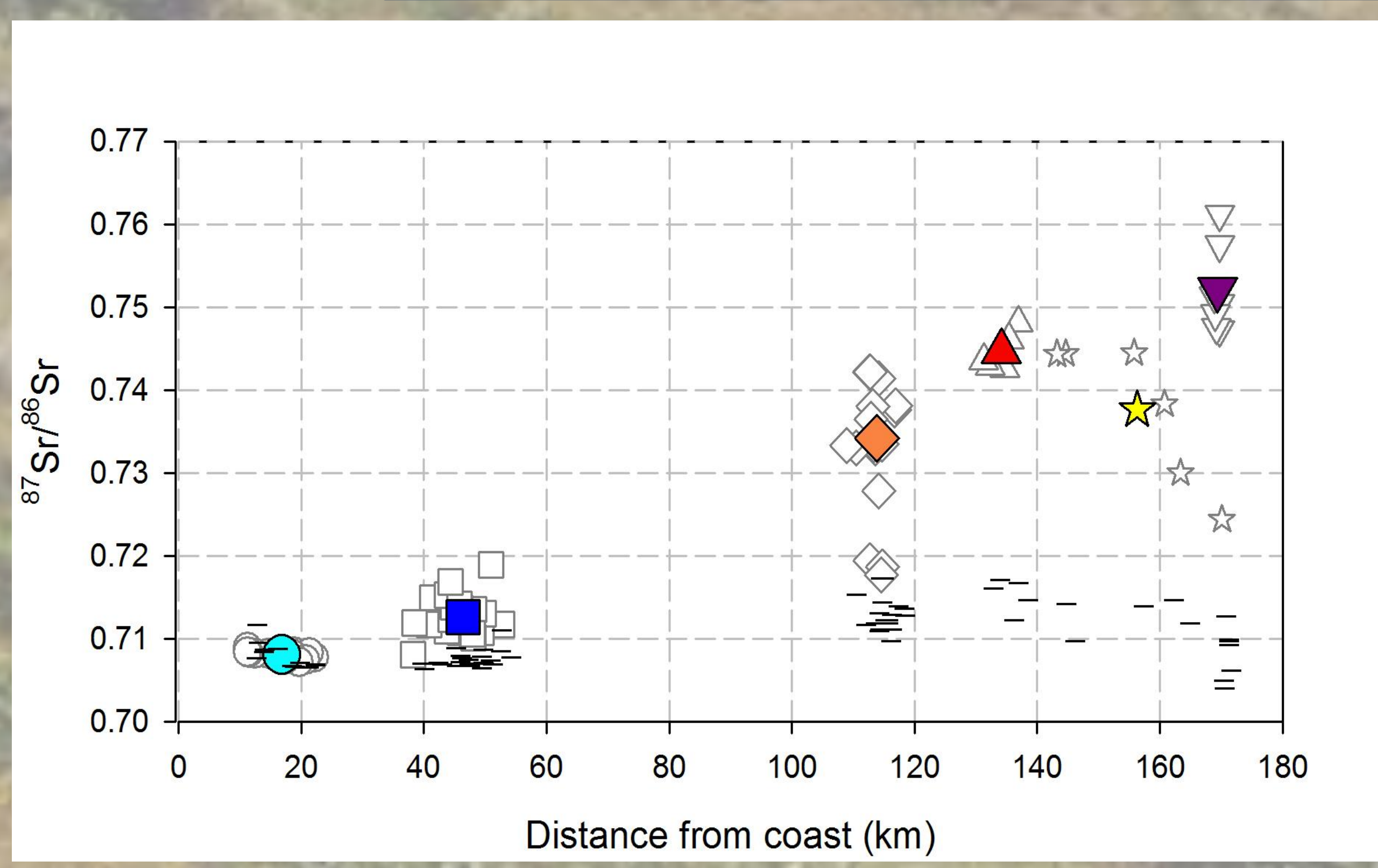

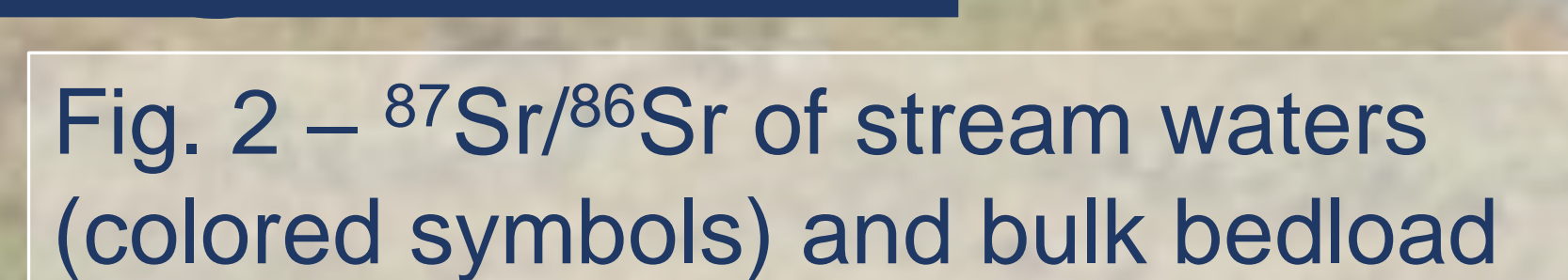
(colored symbols) and bulk bedload
(horizontal black lines) across the ransect (Deuerling et al,., in prep)

Bedload Sr isotopes are elatively consistent across the Streamwater Sr isotopes display increased extent of weathering near the coast.
Bedload Mineral Separates

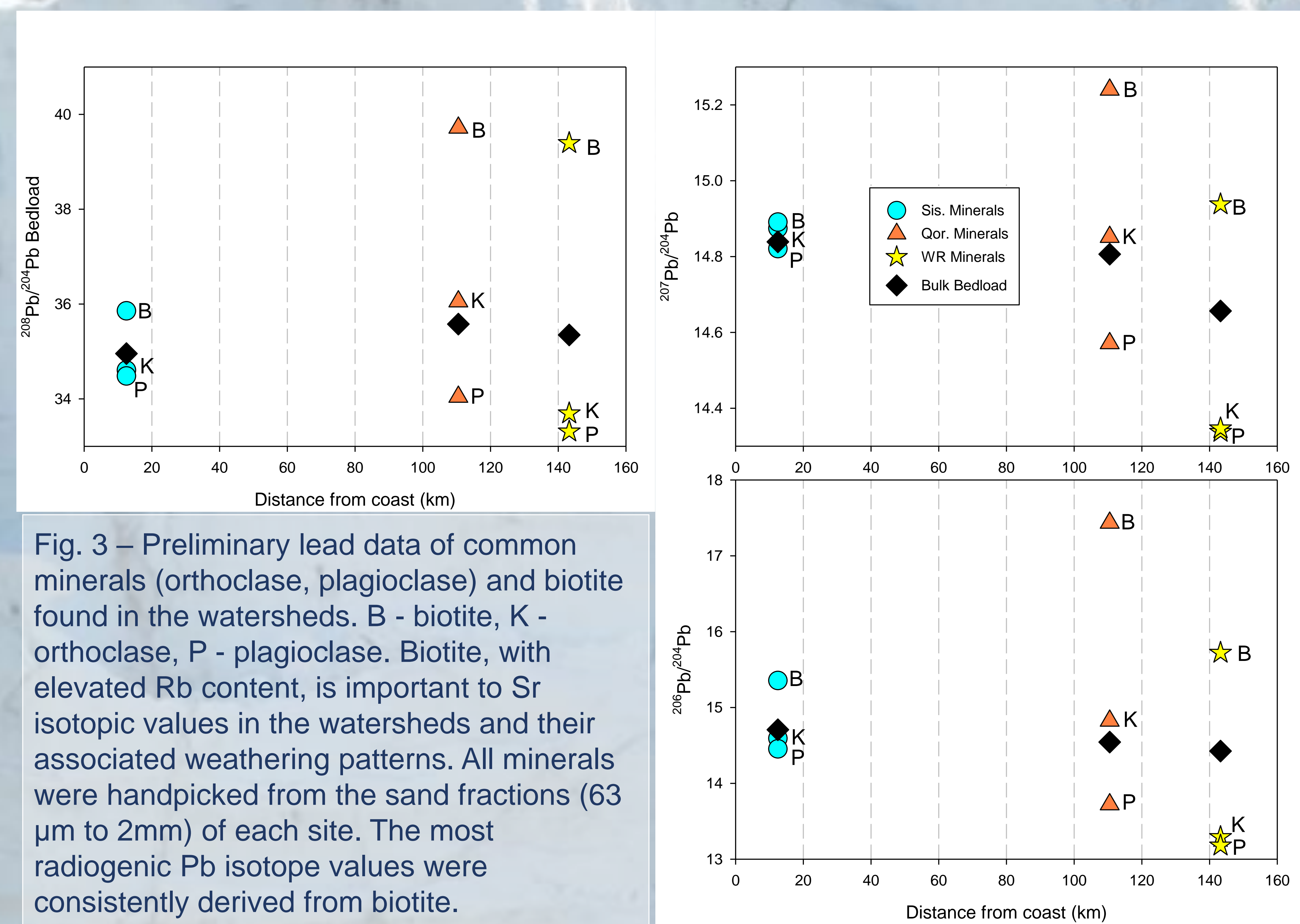

\section{Bedload Size Fractions}

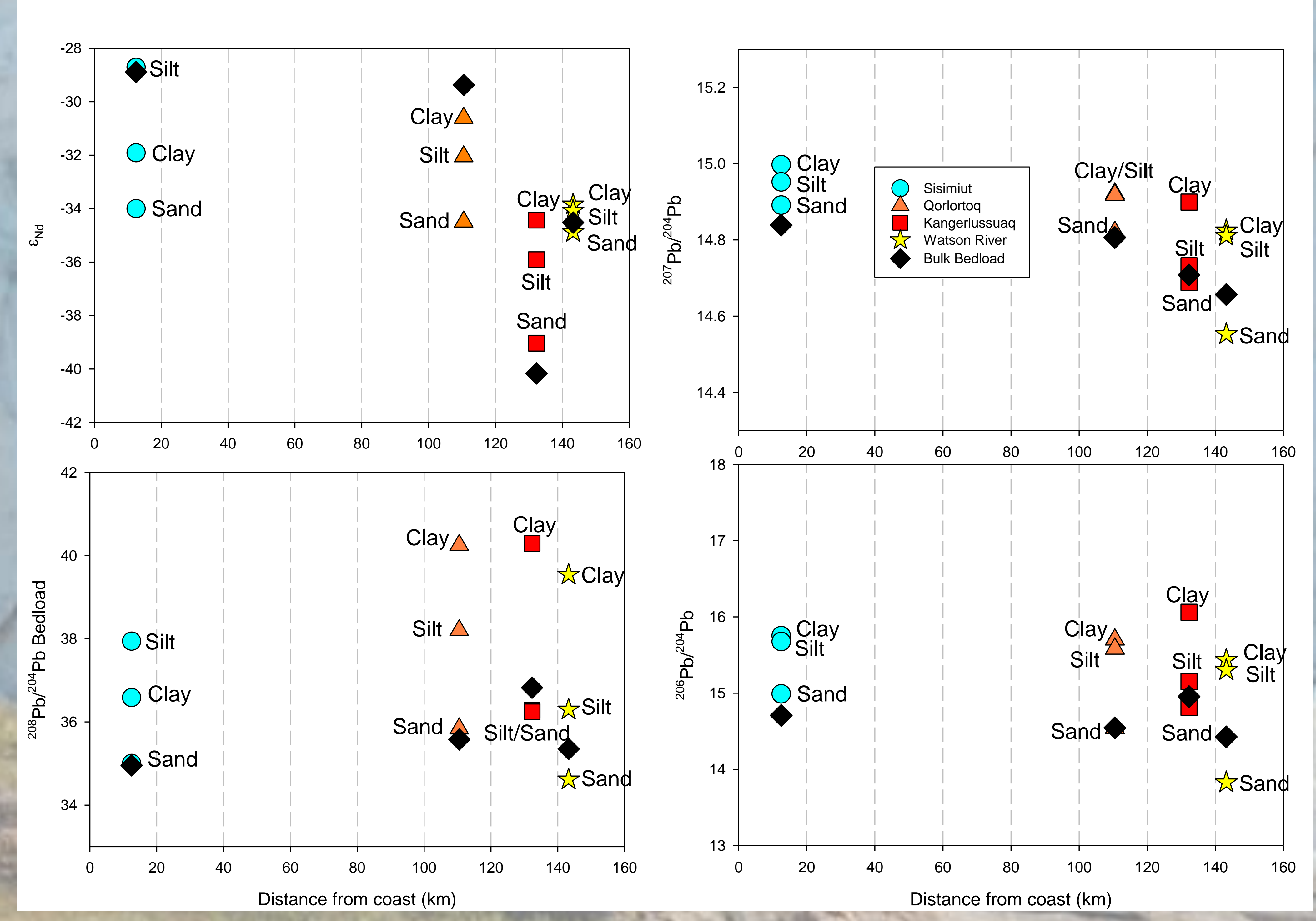

Fig. 4 - Lead and neodymium iscotopic analyses of separated sand, sitt, and clay fractions of
bedload from one coastal deglaciated, two inland deglaciated, and the Watson River rogoglacial watersheds. Different grain size fractions generally produce unique isotopic ratios. The $<2 \mathrm{~mm}$

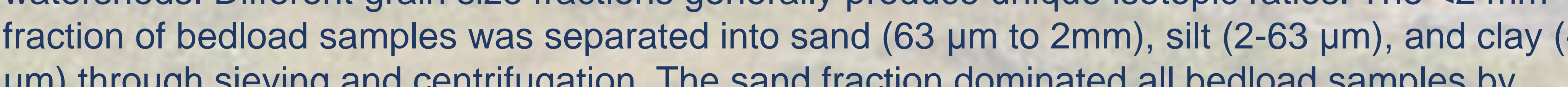

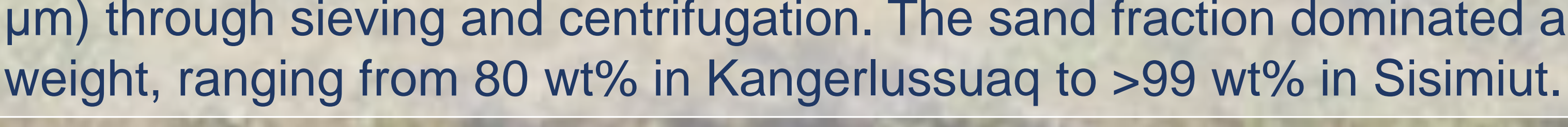

200pp/204pp extracted from moraine soils follows a similar weathering trend to Sr isotopes (not but this signal is complicated by antirropogenic work In general, the most radiogenic ratios of $\mathrm{Pb}$ and $\mathrm{Nd}$ are
and the least radiogenic ratios are in the sand fraction

The coarse fraction (sanda) dominates the size fractions by weight percent and isolopic

- omposition or he buik samples

Bulk isotopic values outside of the range of values for all of the size fractions suggest inherent

作

environment suggesting incompletely developed weathering in this enviricialed that may

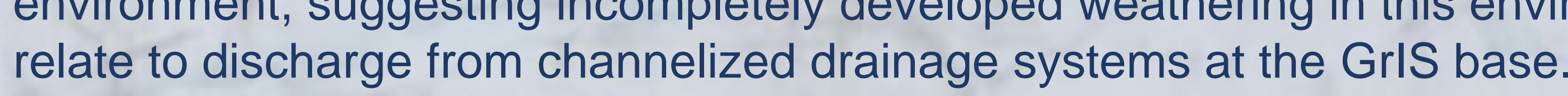

\section{Conclusions}

Bulk bedload data is relatively constant across the glacial foreland

The biotite $\mathrm{Pb}$ isotopic values are variable across the glacial forland. The trend in biotite isotopes generally matches weathering trends documented by Sr isotopes. This sugges mineral separates from the geologic record

Biotite Pb isotopes are less radiogenic in the Watson River proglacial system than at

(a) suggests less chemical weathering in the Qorlortoq watershed than in sediment discharged from the active glacier in the upper Watson River watershed.

A possible explanation for the difference in weathering extent between the inland deglaciated and proglacial watersheds may be tiat actively discharged material in the proglacial system was stored and weathere
system prior to discharge.

The coastal deglaciated environ
mineral separates as expected

The size rractions do not anpear to track any of the chosen minerals and thus may not serve as a suriable record of weathering changes, possibly due to the heterogeneous mixture of

-

Whe isotopic composition of spectic minera separates, such as bionte, has potental lo study available

\section{References}

lum and Erel, 1995, Nature, 373, 415-418. Harlavan and Erel, 2002, GCA, 66, 837-848. Hindshaw et al, 2014, GCA, 145, 50-71. Scribner et al., 2015, GCA, 170, 157-172. Blum and Erel, 2003, Tr. on Geochem., 5, 365- Kurzweil et al., 2010, EPSL, 299, 458-465. 392.
Garcon et al., 2014, Chem. Geol., 364, 42-55.
Harlavan, Et, Erel, Blum, 1998, GCA, 62, 33-46 Bhatia et all, 2011, Jour. of Glac,. 57, 929-94,

\section{Acknowledgements}

We thank George Kamenov for analytical support.
by the NSF Grant PLR-1203773 to JBM and EEM. 